\title{
Instructions to authors
}

Detailed instructions to authors are available online here: cambridge.org/core/journals/journal-of-glaciology/information

\section{The Journal of Glaciology publishes three types of paper:}

- Articles - concerning new findings and theories, or new instruments and methods, in glaciology; or review articles that offer an up-to-date, coherent account of a glaciological subject that is developming rapidly or has been neglected

- Letters - identical in form and general content to Articles, but of reduced length, and carrying substantially reduced processing charges

- Communications - short pieces without abstracts that could be, e.g., comments on published articles/letters, book reviews, or short correspondence on topics of interest to the community

\section{Papers submitted should be:}

- of high scientific quality

- complete and clear

- substantially different from previously published work.

\section{Length}

Papers should be concise. Lines and pages should be numbered. Letters are limited to five Journal pages and Correspondences to two (one Journal page = about 1000 words).

\section{Original submission}

Submit your paper via the Journal of Glaciology online submission system at https://mc.manuscriptcentral.com/jog

\section{Review process}

Your paper will be peer reviewed by at least two reviewers. The Scientific Editor will discuss any alterations required to the paper. The Associate Chief Editor will inform you if and when your paper is accepted for publication. Papers written in poor English, not appropriate for the journal, or of inferior quality will be rejected without review.

You will be sent a proof of your text and illustrations to check and correct in advance of online publication.

\section{Final submission}

The final accepted version of the paper should be in electronic format.

- Acceptable formats are

- Text (including tables and figure captions) - Word, rtf or LaTeX (the IGS class file should be used; downloadable from the website). Please also supply a final PDF

- Figures - ideally in tif or eps format (or otherwise in the format in which they were created)

- Responsibility for the accuracy of all data (including references) rests with the authors

\section{Supplementary material}

The Journal of Glaciology accepts and makes available online appropriate supplementary material. It should be clearly named and labelled and provided in standard file formats.

\section{General points}

- Title should be concise

- Abstract should be less than 200 words
- Papers should be divided into numbered sections with short section headings

- Use SI units

- Use internationally recognized systems of abbreviation

- Illustrations should

- be one or two column widths: up to $85 \mathrm{~mm}$ or up to $178 \mathrm{~mm}$

- not be in boxes

- use strong black lines (avoid tinting if possible)

- use SI units in labels

- use Optima, Arial or a similar sans serif font in labels

- TeX authors: please provide a pdf of the whole paper (text, tables, figures and captions) as well as the individual LaTeX and graphics files

- Equations should

- be set in MathType or advanced equation editor

- NOT be embedded as graphics in the text

- Tables should

- be numbered in Arabic

- be referred to in text (as Table 1 etc.)

- NOT be submitted as illustrations

- All citations in text should include the author name(s) and the year of publication (e.g. Smith, 2010; Smith and Jones, 2012; Smith and others, 2014) and must have an entry in the reference list

- Reference lists should

- be concise

- be complete and accurate, including doi numbers

- be provided in precise Journal format, including punctuation and emphasis (see past papers for style)

- be arranged in alphabetical order by first author's surname

- include works accepted but not published as 'in press'

- not include personal communications, unpublished data or manuscripts in preparation or submitted for publication (these should be included in the text)

\section{Open Access and page charges}

As a gold open access journal, the Journal of Glaciology is published without restriction and receives no subscription revenue. The costs of publication are instead covered by an article publishing charge (APC) levied upon the corresponding author, or his/her funding body or institution.

The APC for non-IGS members is $£ 1,320$ for a regular article (of 6 published pages or more), $£ 660$ for a letter (of 5 published pages or fewer) and $£ 300$ for a communication (of 2 published pages or fewer). IGS members receive a $10 \%$ discount on these charges.

Figures quoted here are correct for 2021.

Upon acceptance for publication the corresponding author will be contacted by Rightslink on behalf of Cambridge University Press, who will administer the collection of the article publishing charge. At that stage the corresponding author can pay by credit card or arrange for an invoice to be issued to his/her funding body or institution. Selected authors may be granted an APC waiver by the IGS. In such cases, a waiver code shall be provided, which should be issued to Rightslink upon receipt of the payment. 


\section{Journal of}

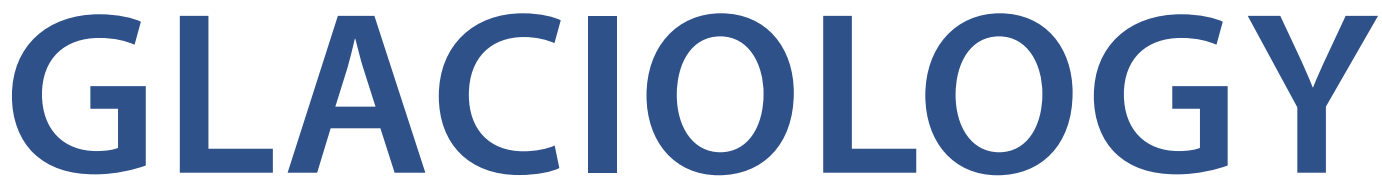

\section{CONTENTS Vol 67 No $265 \quad 2021$}

\begin{abstract}
777-787 Seismic observations of a complex firn structure across the Amery Ice Shelf, East Antarctica

Hannes Hollmann, Adam Treverrow, Leo E. Peters, Anya M. Reading and Bernd Kulessa
\end{abstract}

788-796 Porosity dependence of elastic moduli of snow and firn

Colin M. Sayers

797-810 Glacier-plume or glacier-fjord circulation models? A 2-D comparison for HansbreenHansbukta system, Svalbard

Eva De Andrés, Jaime Otero, Francisco J. Navarro and Waldemar Walczowski

811-823 Glacier clear ice bands indicate englacial channel microbial distribution

Gilda Varliero, Alexandra Holland, Gary L. A. Barker, Marian L. Yallop, Andrew G. Fountain and

Alexandre M. Anesio

824-832 Ice thickness estimates of Lemon Creek Glacier, Alaska, from active-source seismic imaging Stephen A. Veitch, Marianne Karplus, Galen Kaip,

Lucia F. Gonzalez, Jason M. Amundson and

Timothy C. Bartholomaus

833-846 Complex multi-decadal ice dynamical change inland of marine-terminating glaciers on the Greenland Ice Sheet

Joshua J. Williams, Noel Gourmelen and

Peter Nienow

847-861 A casting method using contrastenhanced diethylphthalate for micro-computed tomography of snow

Michael Lombardo, Martin Schneebeli and Henning Löwe

862-874 Combining UAV and Landsat data to assess glacier changes on the central Tibetan Plateau

Yuang Xue, Zhefan Jing, Shichang Kang, Xiaobo He and Chenyu $\mathrm{Li}$

875-884 Thermal refraction: implications for subglacial heat flux

Simon Willcocks, Derrick Hasterok and

Samuel Jennings

885-902 Treatment of ice-shelf evolution combining flow and flexure

Douglas R. MacAyeal, Olga V. Sergienko,

Alison F. Banwell, Grant J. Macdonald, Ian C. Willis and Laura A. Stevens
903-908 Pure rotational Raman spectroscopy applied to $\mathrm{N}_{2} / \mathrm{O}_{2}$ analysis of air bubbles in polar firn Hiroshi Ohno, Yoshinori lizuka and Shuji Fujita

909-920 Modeling the impacts of climate change on mass balance and discharge of Eklutna Glacier, Alaska, 1985-2019

Jason Geck, Regine Hock, Michael G. Loso,

Johnse Ostman and Roman Dial

921-932 Water content of firn at Lomonosovfonna, Svalbard, derived from subsurface temperature measurements

Sergey A. Marchenko, Ward J. J. van Pelt, Rickard Pettersson, Veijo A. Pohjola and Carleen H. Reijmer

933-951 The triggers of the disaggregation of Voyeykov Ice Shelf (2007), Wilkes Land, East Antarctica, and its subsequent evolution Jennifer F. Arthur, Chris R. Stokes,

Stewart S. R. Jamieson, Bertie W. J. Miles,

J. Rachel Carr and Amber A. Leeson

952-960 Physical limits to meltwater penetration in firn

Neil F. Humphrey, Joel T. Harper and

Toby W. Meierbachtol

Letters

961-966 Seasonal dynamics of snow ablation on selected glaciers in central Spitsbergen derived from Sentinel-2 satellite images Jan Kavan and Vincent Haagmans

967-973 Recent surging event of a glacier on Geladandong Peak on the Central Tibetan Plateau Junli Xu, Donghui Shangguan and Jian Wang

\section{Communication}

974-975 Book review: K. Hutter, 2020.

Fundamental Glaciology: modelling

thermomechanical processes of ice in the geophysical environment, engineering and material science. International Glaciological Society

Colin R. Meyer

\section{Erratum}

976 On the errors involved in ice-thickness estimates I: ground-penetrating radar measurement errors - ERRATUM

J.J. Lapazaran, J. Otero, A. Martín-Español and F.J. Navarro

Front cover In order to acquire X-ray tomography data of snow collected in the field, deformation and metamorphism of the fragile ice structures must be prevented. A new contrast-enhanced casting method helps to do this efficiently. Photo courtesy of WSL Institute for Snow and Avalanche Research SLF. Related article doi: $10.1017 /$ jog.2021.35
Cambridge Core

For further information about this journal please go to the journal website at: cambridge.org/jog

\section{MIX}

Paper from responsible sources $\underset{\text { www.fsc.org }}{\text { FSC }}$ FSC $^{\circledR}$ C007785

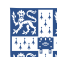

